\title{
Chlamydia trachomatis infection of human fallopian tube organ cultures
}

\author{
Morris D. COOPER, ${ }^{1 *}$ Judy RapP, ${ }^{1}$ Christine JefFery-Wiseman, ${ }^{1}$ Robert C. Barnes ${ }^{2}$ \\ and DAVID S. STEPHENS ${ }^{3}$
}

\begin{abstract}
${ }^{1}$ Department of Medical Microbiology and Immunology, Southern Illinois University School of Medicine, Springfield, Illinois 62794-9230, USA

${ }^{2}$ Sexually Transmitted Disease Laboratory Program, Center for Infectious Diseases, Centers for Disease Control, Atlanta, Georgia 30333, USA

${ }^{3}$ Department of Medicine, Division of Infectious Diseases, Emory University School of Medicine, and Veterans

Administration Medical Center, Atlanta, Georgia 30303, USA
\end{abstract}

(Received 30 October 1989; revised 7 February 1990; accepted 12 February 1990)

\begin{abstract}
The pathogenic events that precede Chlamydia trachomatis salpingitis in the human fallopian tube have not been fully described. We used a model of human fallopian tubes in organ culture (HFTOC) infected with strain E/UW$5 / C X$ of $C$. trachomatis to study these events. The model supported sustained $C$. trachomatis infection as demonstrated by recovery of viable $C$. trachomatis from medium and tissue over 5-7 d. However, the level of infectivity was low. Maximal infection occurred at $72 \mathrm{~h}$ after initial inoculation. In contrast to gonococcal infection of the HFTOC, $C$. trachomatis did not damage overall ciliary function of HFTOC. However, a local direct cytotoxic effect characterized by loss of microvilli and disruption of cell junctions was noted when multiple chlamydial elementary bodies attached to mucosal cells. Beginning at $24 \mathrm{~h}$, and continuing throughout the course of $C$. trachomatis infection of HFTOC, ruptured epithelial cells releasing elementary bodies were noted. Chlamydial inclusions were seen in the mucosa by $72 \mathrm{~h}$ in $\sim 6 \%$ of both ciliated and nonciliated epithelial cells. Mucosal inclusions contained all forms of the $C$. trachomatis developmental cycle. These data suggest that factors present in the human fallopian tube may limit susceptibility to chlamydial infection but support the use of the HFTOC model in the study of the pathogenesis of $C$. trachomatis salpingitis.
\end{abstract}

\section{Introduction}

Chlamydia trachomatis has emerged as the most common sexually transmitted bacterial pathogen in developed countries (Washington et al., 1987; Aral \& Holmes, 1990). In women, genital infection due to $C$. trachomatis may be asymptomatic or result in mucocervicitis, acute urethritis or salpingitis. Salpingitis is potentially the most devastating of these infections. Damage to the fallopian tube caused by $C$. trachomatis may lead to recurrent salpingitis, tubo-ovarian abscess, ectopic pregnancy and infertility. A knowledge of the steps by which C. trachomatis causes salpingitis is critical to the development of strategies for controlling and preventing this infection.

Although the human fallopian tube organ culture (HFTOC) model has been used to define the patho-

Abbreviations: EB, elementary body; HFTOC, human fallopian tubes in organ culture; IFU, inclusion-forming unit; LM, light microscopy; SEM, scanning electron microscopy; TEM, transmission electron microscopy. genesis of gonococcal salpingitis (McGee et al., 1976; Ward et al., 1974), only one study has used this model to study $C$. trachomatis pathogenesis. Hutchinson et al. (1979) used fallopian tube organ cultures of both bovine and human origin to study infection by $C$. trachomatis. They noted that HFTOCs in vitro could be infected with recovery of $C$. trachomatis during the third to fifth day of infection. However, chlamydial inclusions could not be detected in the HFTOCs and the microscopic events occurring during the infection were not determined. In the current study we used light and electron microscopy as well as quantitative culturing to define events in the infection of HFTOCs with $C$. trachomatis.

\section{Methods}

Micro-organisms and culture techniques. The $C$. trachomatis strain used in this study was serotype $\mathrm{E} / \mathrm{UW}-5 / \mathrm{CX}$. The $\mathrm{E}$ strain of $C$. trachomatis is well characterized (Kuo et al., 1972) and has previously been shown to be capable of infecting explants from primate and human fallopian tubes of endometrial and ectocervical epithelium in 
culture (Patton, 1985; Patton et al., 1983, 1987a, b). To maintain stocks of this strain, it was passaged in HeLa 229 cells for nine passages, concentrated to $1 \times 10^{8}$ inclusion-forming units (IFU) $\mathrm{ml}^{-1}$ and stored at $-80^{\circ} \mathrm{C}$ in HEPES-sucrose-calcium (HSC) buffer (Bird \& Forrester, 1981).

The monolayer of HeLa cells was infected by pretreating these cells with DEAE-dextran ( $30 \mu \mathrm{g} \mathrm{ml}^{-1}$ in HSC buffer) for $20 \mathrm{~min}$ at room temperature. The monolayer was then rinsed with Hanks' balanced salt solution and inoculated with $1-2 \mathrm{ml}$ of the serotype $\mathrm{E}$ inoculum $\left(10^{8} \mathrm{IFU}\right)$. The inoculum was prepared by rapidly thawing the chlamydiae and briefly sonicating them to eliminate clumping of elementary bodies (EBs). The flasks containing the infected monolayers were then incubated at $37^{\circ} \mathrm{C}$ for $1 \mathrm{~h}$ with the flasks being rotated every 5-10 min. The inoculum was then removed, and the monolayer was rinsed with Hanks' balanced salt solution and was covered with $20-40 \mathrm{ml}$ of medium containing cycloheximide and glucose. The flasks were then incubated at $37{ }^{\circ} \mathrm{C}$ in $5 \%(v / v) \mathrm{CO}_{2}$ for $48 \mathrm{~h}$. At $48 \mathrm{~h}$, the inoculum gave $\sim 90 \%$ infectivity of the $\mathrm{HeLa}$ cell monolayer. The medium was removed and $5 \mathrm{ml}$ of $\mathrm{HSC}$ and about $60-70$ glass beads ( $3 \mathrm{~mm}$ diameter) were added, to dislodge the cells. The cells were collected and chlamydial inclusions were released by sonication for $30 \mathrm{~s}$ at full power. A low-speed centrifugation (1200 r.p.m. for $10 \mathrm{~min}$ ) removed the cell debris. The supernatant from the low-speed centrifugation was centrifuged at 16000 r.p.m. to pellet the EBs. The pellet was resuspended in $20 \mathrm{ml}$ HSC, sonicated to remove EB clumps and $1 \mathrm{ml}$ portions were frozen.

The moculum was titrated by the following method. The chlamydial suspension was thawed, sonicated and diluted 10 -fold from $10^{-1}$ to $10^{-7}$ in HSC. All dilutions were performed at $4^{\circ} \mathrm{C}$. HeLa cell monolayers grown on $12 \mathrm{~mm}$ coverslips were each infected in duplicate with $0.1 \mathrm{ml}$ of the dilutions of $C$. trachomatis. The infected vials were centrifuged at $2500 \mathrm{~g}$ for $60 \mathrm{~min}$ at $37^{\circ} \mathrm{C}$. After centrifugation, the inoculum was aspirated, and $1 \mathrm{ml}$ of medium containing cycloheximide and glucose was added to each vial followed by incubation at $37^{\circ} \mathrm{C}$ in $5 \% \mathrm{CO}_{2}$ for $48 \mathrm{~h}$. After incubation, the coverslips were fixed in $95 \%(\mathrm{v} / \mathrm{v})$ ethanol and stained with fluorescein-labelled monoclonal antibodies (Syva Microtrak). Stained inclusions were counted and the log of the average number of IFU per coverslip was plotted against the dilution used for inoculation. To calculate the IFU per ml of the initial suspension, the antilog of the $y$-intercept was multiplied by the dilution factor. After calculating this number, the IFU contained in any less dilute concentration could be obtained.

Infection of HFTOC. HFTOC were established as previously described (McGee et al., 1976). Briefly, fallopian tubes were obtained from nonpregnant, premenopausal women undergoing hysterectomy for prolonged uterine bleeding or fibroid tumours as well as from women undergoing salpingectomy for sterilization. Tubes were removed from the patient and placed in Eagle's minimal essential medium (MEM) containing Earle's salts and L-glutamine and buffered with $0.05 \mathrm{M}$-HEPES to a $\mathrm{pH}$ of 7.5. The HEPES-MEM also contained colistin $\left(3 \mu \mathrm{g} \mathrm{ml}^{-1}\right)$ and vancomycin $\left(5 \mu \mathrm{g} \mathrm{ml}^{-1}\right)$. After removal of the adventitial tissues, the fallopian tubes were cut longitudinally and 3-4 $\mathrm{mm}^{2}$ pieces were cut with a scalpel blade and transferred to tissue culture dishes containing $3 \mathrm{ml}$ HEPES-MEM plus antibiotics for $24 \mathrm{~h}$. In all experiments the organ cultures were washed free of antibiotics after the $24 \mathrm{~h}$ incubation and maintained in media free of antibiotics during the experiment. The cultures were maintained at $37^{\circ} \mathrm{C}$ in $5 \%$ $\mathrm{CO}_{2}$.

The HeLa-passaged serotype E strain was used to infect the HFTOC. EBs were quickly thawed and placed on ice. The EB suspension was sonicated for $30 \mathrm{~s}$ and diluted in HSC to approximately $1 \times 10^{8}$ IFU $\mathrm{ml}^{-1}$ and $50 \mu \mathrm{l}$ of this inoculum was added to each HFTOC. For chlamydial infection, HFTOC were prepared using 24-well tissue culture plates. A single piece of fallopian tube tissue $\left(3-4 \mathrm{~mm}^{2}\right)$ was placed in each well and covered with $1 \mathrm{ml}$ of antibiotic-free medium and incubated for periods up to $10 \mathrm{~d}$. At $4 \mathrm{~h}, 8 \mathrm{~h}, 24 \mathrm{~h}, 48 \mathrm{~h}, 72 \mathrm{~h}, 5 \mathrm{~d}$ and $10 \mathrm{~d}$, tissues were removed and processed for light microscopy (LM), scanning electron microscopy (SEM), and transmission electron microscopy (TEM). Ciliary activity of organ cultures was also assessed at those time intervals by the techniques previously described (McGee et al., 1976). To quantify chlamydial infection, HFTOC samples were washed and homogenized; then the homogenate was used to infect HeLa cell monolayers. Samples of the tissue culture medium from the infected HFTOC were also used to infect HeLa cell monolayers in order to further quantify the infection of the HFTOC. At each time interval uninfected tissues were processed for microscopy, examined for ciliary activity and cultured as a control for tissue integrity as well as for previous undiagnosed chlamydia infection.

Microscopy (i) SEM. HFTOC to be examined by SEM were fixed in $2 \%(\mathrm{w} / \mathrm{v})$ glutaraldehyde $(\mathrm{pH} 7.3)$ in $0.1 \mathrm{M}$-sodium cacodylate. Postfixation was accomplished in $1.5 \%(\mathrm{w} / \mathrm{v})$ osmium tetroxide in the same buffer. HFTOC were dehydrated in ethanol, critical-point dried, coated with gold/palladium and examined in a scanning electron microscope (model S-500; Hitachi Scientific Instruments).

(ii) $L M$ and TEM. HFTOC to be examined by TEM were fixed in $2.5 \%$ glutaraldehyde in $0.13 \mathrm{M}$-phosphate buffer ( $\mathrm{pH} \mathrm{7.2).} \mathrm{After}$ fixation for $12-24 \mathrm{~h}$, the tissues were transferred to $0.13 \mathrm{M}$-phosphate buffer ( $\mathrm{pH} 7 \cdot 2$ ) containing $7.5 \%(\mathrm{w} / \mathrm{v})$ sucrose. HFTOC were post-fixed for $1-2 \mathrm{~h}$ in $1.5 \%$ osmium tetroxide, dehydrated in graded solutions of ethanol and embedded in Spurr resin (Electron Microscopy Scientific). Sections of tissue $1-2 \mu \mathrm{m}$ thick were stained with $1 \%(\mathrm{w} / \mathrm{v})$ toluidine blue in $1 \%(w / v)$ borax for 15 to $30 \mathrm{~s}$; the stained sections were examined by LM. Sections $40-60 \mathrm{~nm}$ thick were stained with uranyl acetate and lead citrate before examination in a transmission electron microscope (model 300; Philips Electronics).

\section{Results}

\section{Infection of HFTOCs by C. trachomatis}

Both culture medium and HFTOC homogenates were cultured to quantify $C$. trachomatis infection of HFTOC. Because $C$. trachomatis is an obligate intracellular parasite, medium and tissue assayed after the first $24 \mathrm{~h}$ of infection should reflect active intracellular multiplication.

Fig. 1(a) shows the number of $C$. trachomatis IFU recovered from the medium of infected HFTOC. The original inoculum was $5 \times 10^{6} \mathrm{IFU} \mathrm{ml} \mathrm{m}^{-1}$. At $24 \mathrm{~h}$ postinfection there were $1.3 \times 10^{2} \mathrm{IFU} \mathrm{ml}^{-1}$ in the HFTOC culture medium. More IFU $\left(5 \cdot 2 \times 10^{3}\right)$ were recovered at $48 \mathrm{~h}$, with the maximum number $\left(1.86 \times 10^{4}\right)$ recovered at $72 \mathrm{~h}$. Chlamydiae were recovered at $5 \mathrm{~d}$ post-infection $\left(3.9 \times 10^{3}\right)$ and up to $7 \mathrm{~d}$ post-infection. Culture medium from uninfected HFTOC did not yield $C$. trachomatis, indicating the absence of concomitant natural infection.

Recovery of $C$. trachomatis from homogenates of HFTOC is shown in Fig. 1(b). Following infection with $5 \times 10^{6} \mathrm{IFU} \mathrm{ml}^{-1}$, the counts of IFU (mg tissue) $)^{-1}$ were $1.2 \times 10^{1}$ at $24 \mathrm{~h}, 4.3 \times 10^{1}$ at $48 \mathrm{~h}, 2.6 \times 10^{2}$ at $72 \mathrm{~h}$ and $2.6 \times 10^{1}$ at $5 \mathrm{~d}$ post-infection. Infection in HFTOC persisted for at least $5 \mathrm{~d}$. 

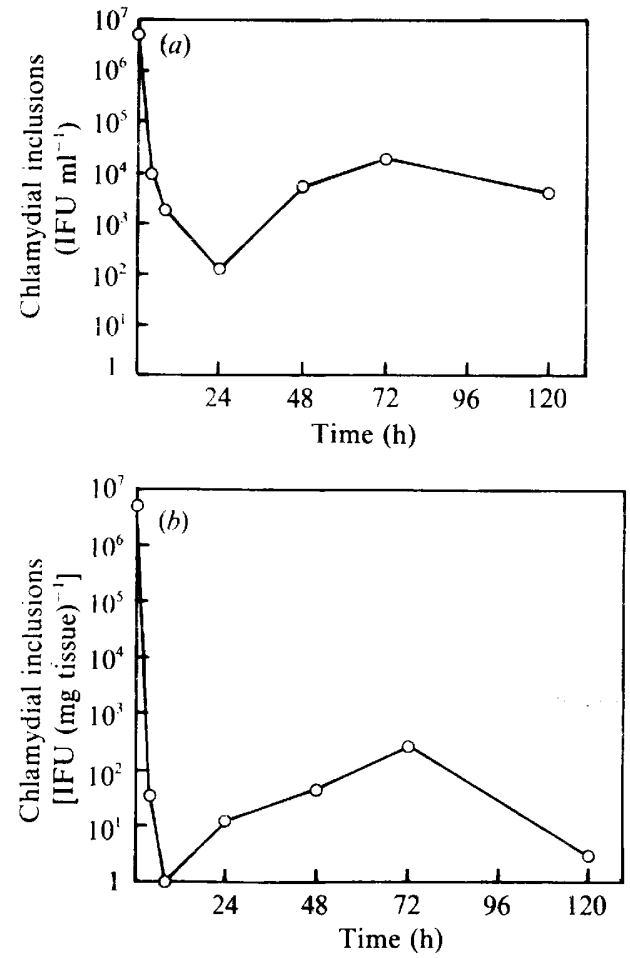

Fig. 1. Recovery of $C$. trachomatis from (a) the culture medium and (b) homogenates of infected HFTOC. The initial infection contained $5 \times 10^{6} \mathrm{IFU} \mathrm{ml}^{-1}$.

Effect of C. trachomatis infection on ciliary activity of HFTOC

Ciliary activity as monitored by percentage peripheral ciliary activity and ciliary vigour was assessed (McGee $e t$ al., 1976) during the course of $C$. trachomatis infection of HFTOC. In three separate experiments no loss of ciliary activity was detected by either criterion when $C$. trachomatis-infected HFTOC were compared with uninfected cultures (data not shown). These data are in sharp contrast to gonococcal infections of HFTOC, which show marked damage to ciliary activity using identical assays (McGee et al., 1976).

\section{Events in the interactions of $C$. trachomatis and human fallopian tube mucosa as noted by SEM}

Microscopic events during $C$. trachomatis infection of HFTOC were studied with techniques previously used to define gonococcal infection of this model. Fig. 2 shows uninfected HFTOC after $7 \mathrm{~d}$ incubation. The mucosal surface was undisturbed, showing numerous ciliated and nonciliated cells. The microvilli of the nonciliated cells were prominent and uniform. The ciliated cells were intact. These characteristics of the mucosa were maintained in uninfected HFTOC through $7-10 \mathrm{~d}$ of incubation.

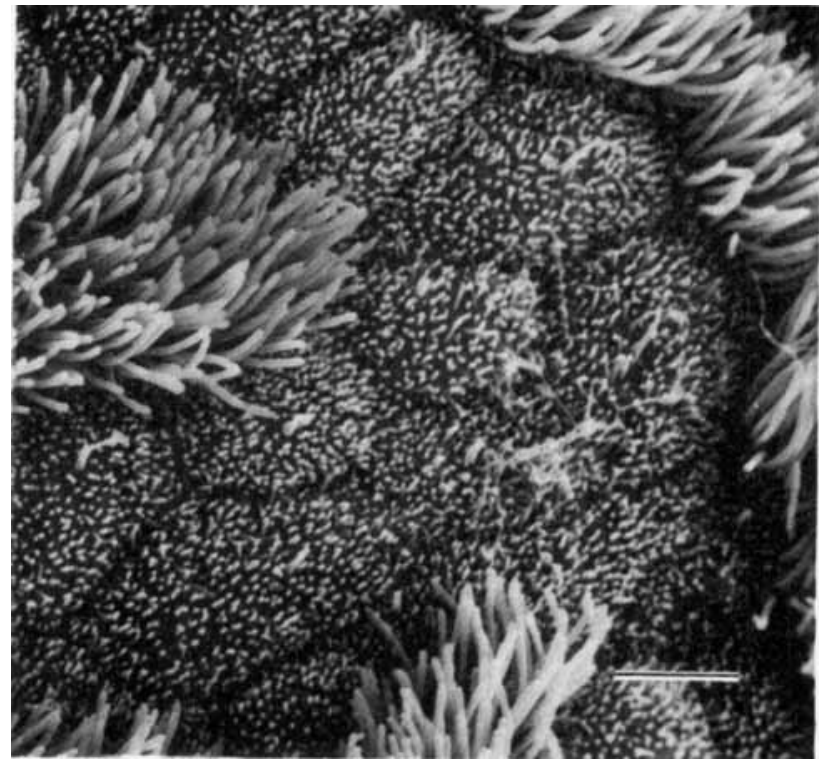

Fig. 2. Scanning electron micrograph of uninfected HFTOC after $7 \mathrm{~d}$ of culture. Bar, $2 \mu \mathrm{m}$.

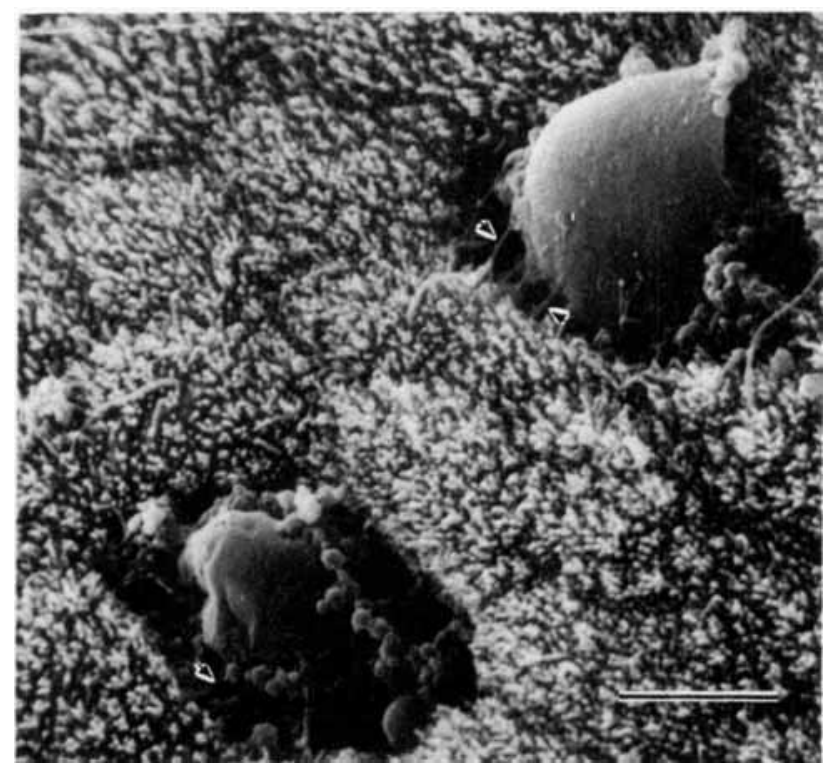

Fig. 3. Scanning electron micrograph of clusters of EBs attaching to nonciliated epithelial cells at $4 \mathrm{~h}$ post-infection. Where aggregates of elementary bodies attach there is local cytotoxicity marked by the loss of microvilli on these cells and a disruption of cellular junctions. The arrows indicate residual strands connecting the infected cell to the rest of the mucosa. Bar, $4 \mu \mathrm{m}$.

Strikingly different results were observed during C. trachomatis infections of HFTOC. Fig. 3 illustrates the cytotoxic effects seen at $4 \mathrm{~h}$ following attachment of multiple $C$. trachomatis EBs. Nonciliated cells, with multiple EBs attached, began to lose surface integrity as noted by the lack of microvilli and the disruption of 


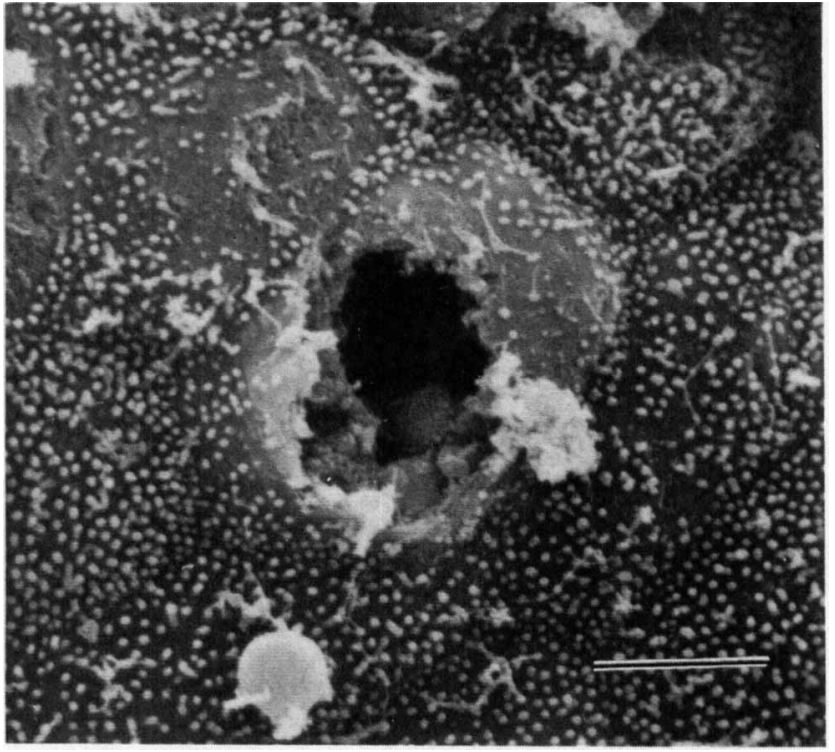

Fig. 4. Scanning electron micrograph of infected HFTOC $72 \mathrm{~h}$ after infection, showing a cell with a lesion left by the rupturing of $C$. trachomatis inclusions. Bar, $5 \mu \mathrm{m}$.

cellular junctions. Also noted were residual strands (arrowed in Fig. 3) connecting the infected cell to the rest of the mucosa.

Associated with the initial attachment and infection of HFTOC was the formation of bundles of fused microvilli (not shown) on nonciliated epithelial cells. These bundles of microvilli were not seen in uninfected HFTOC that were processed under identical conditions at the corresponding time period. The role of these aggregated microvilli in $C$. trachomatis infection of the human fallopian tube is unclear.

Fig. 4 illustrates an HVTOC $72 \mathrm{~h}$ after infection. Cavities in the mucosa, presumably left by rupturing of the chlamydial inclusions, were noted. These cavities were first seen at $72 \mathrm{~h}$ and were present throughout the remaining course of infection. EBs could be seen in some of the ruptured cells.

Intracellular events in the interaction of $C$. trachomatis and human fallopian tube mucosa as noted by LM and TEM

Intracellular $C$. trachomatis were prominent in LM and TEM preparations of HFTOCs infected for $72 \mathrm{~h}$. Inclusions were seen within the mucosa at this time point in $\sim 6 \%$ of both ciliated and nonciliated cells.

Figure $5(a)$ shows a ruptured epithelial cell at $72 \mathrm{~h}$ post-infection, containing EBs, reticulate bodies and intermediate forms. The finding of numerous inclusions at $72 \mathrm{~h}$ corresponded to the recovery of the highest number of $C$. trachomatis IFU from infected supernatants and tissue and the greater number of disrupted epithelial cells noted by SEM. Higher magnification (Fig. $5 b$ ) reveals the loss of both phagosomal and surfaceexposed cytoplasmic membrane integrity with the release of infectious particles to the epithelial surface. However, the cytoplasmic membrane adjacent to other epithelial cells appears to be intact as shown by a continuous membrane and desmosomes. Fig. 6 shows an infected ciliated epithelial cell. Again various stages of the $C$. trachomatis developmental cycle were noted in the cytoplasm. Interestingly, the chlamydiae were no longer membrane bound.

\section{Discussion}

The sequence of events that occurs during infection of the human fallopian tube with $C$. trachomatis has been assumed to be similar to the events seen in C. trachomatis infection of animals or tissue culture and in vivo chlamydial conjunctival infection. Tuffrey and coworkers (Tuffrey \& Taylor-Robinson, 1981; Tuffrey et al., 1982, 1984, 1985, 1986) developed a mouse model of chlamydial genital tract infection using a variety of human isolates of $C$. trachomatis. They found that infection was enhanced by progesterone, which is thought to maintain epithelial cells on the uterine surface. The murine model also offers advantages for immunological studies. Their studies implied that $\mathrm{T}$-cell impairment may play a role in the severity of chlamydial infections and concluded that genetic differences in mice altered their resistance to infection as well as their susceptibility to inflammatory changes. Further, different human isolates do not have equal abilities to produce salpingitis in mice, implying a genetic component to the infectivity of these isolates. Intravaginal inoculation of mice with the agent of mouse pneumonitis (MoPn; a $C$. trachomatis biovar) results in cervical infection, and chlamydial inclusions are found in superficial cervical epithelial cells (Barron et al., 1981). Recently it has been shown that inoculation directly into the ovarian bursa of these mice consistently results in salpingitis (Swenson $e t$ $a l ., 1983)$. Inclusions were readily demonstrated in the oviductal and uterine epithelium. Permanent tubal damage and infertility occurred in the majority of infected mice.

Patton et al. (1983) studied acute C. trachomatis salpingitis in pig-tailed macaque monkeys. In these studies, a single inoculation caused self-limiting tubal inflammation and little residual damage was demon- 

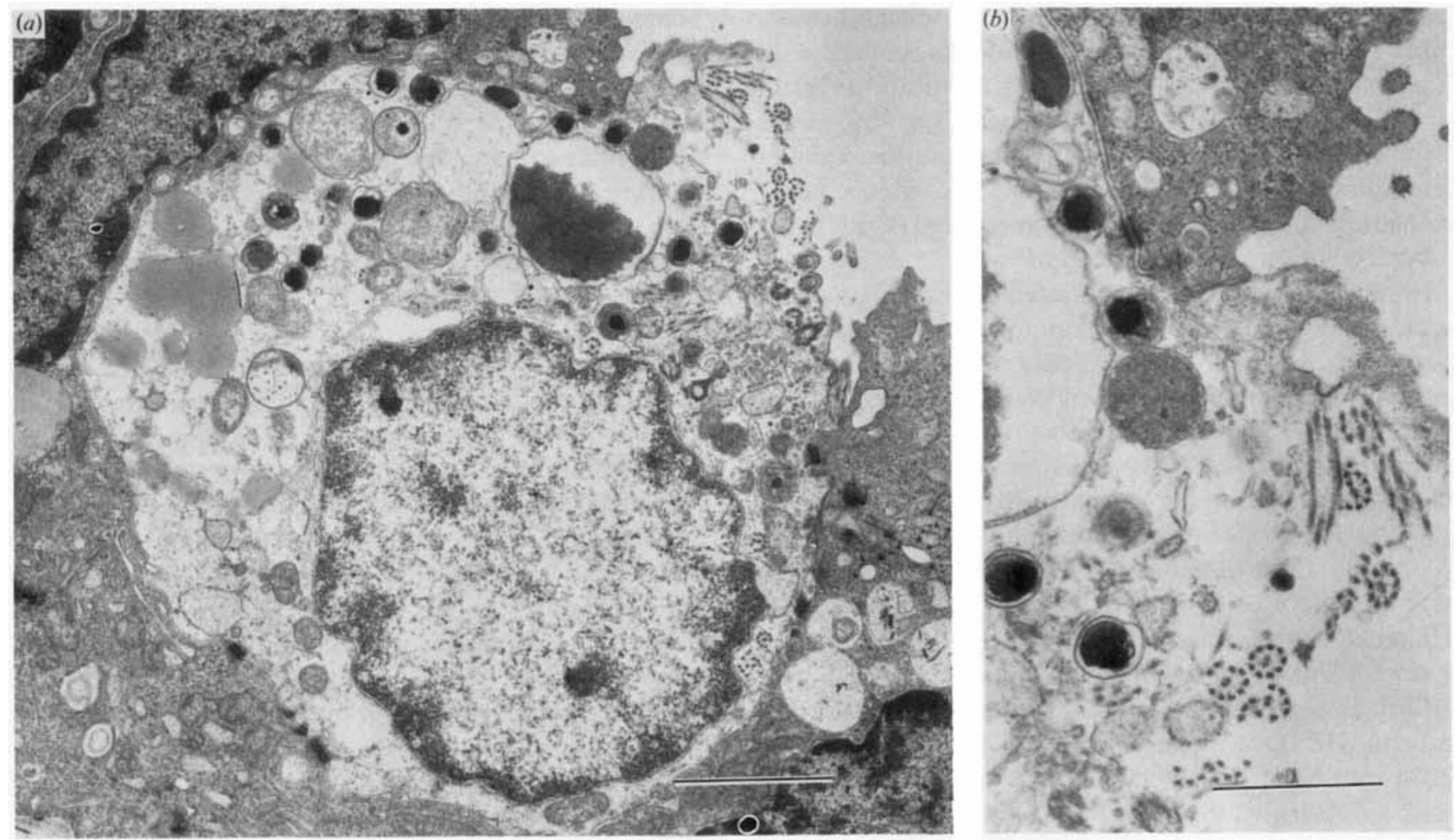

Fig. 5. (a) Transmission electron micrograph of a rupturing epithelial cell at $72 \mathrm{~h}$ post-infection. Note that all forms (EBs, reticulate bodies and intermediate forms) of the developmental cycle are visible in the cytoplasm. Bar, $2 \mu \mathrm{m}$. (b) Higher magnification of the rupturing cell, illustrating the release of the EBs and intermediate forms, and the disruption of the cell membrane. Bar, $1 \mu \mathrm{m}$.

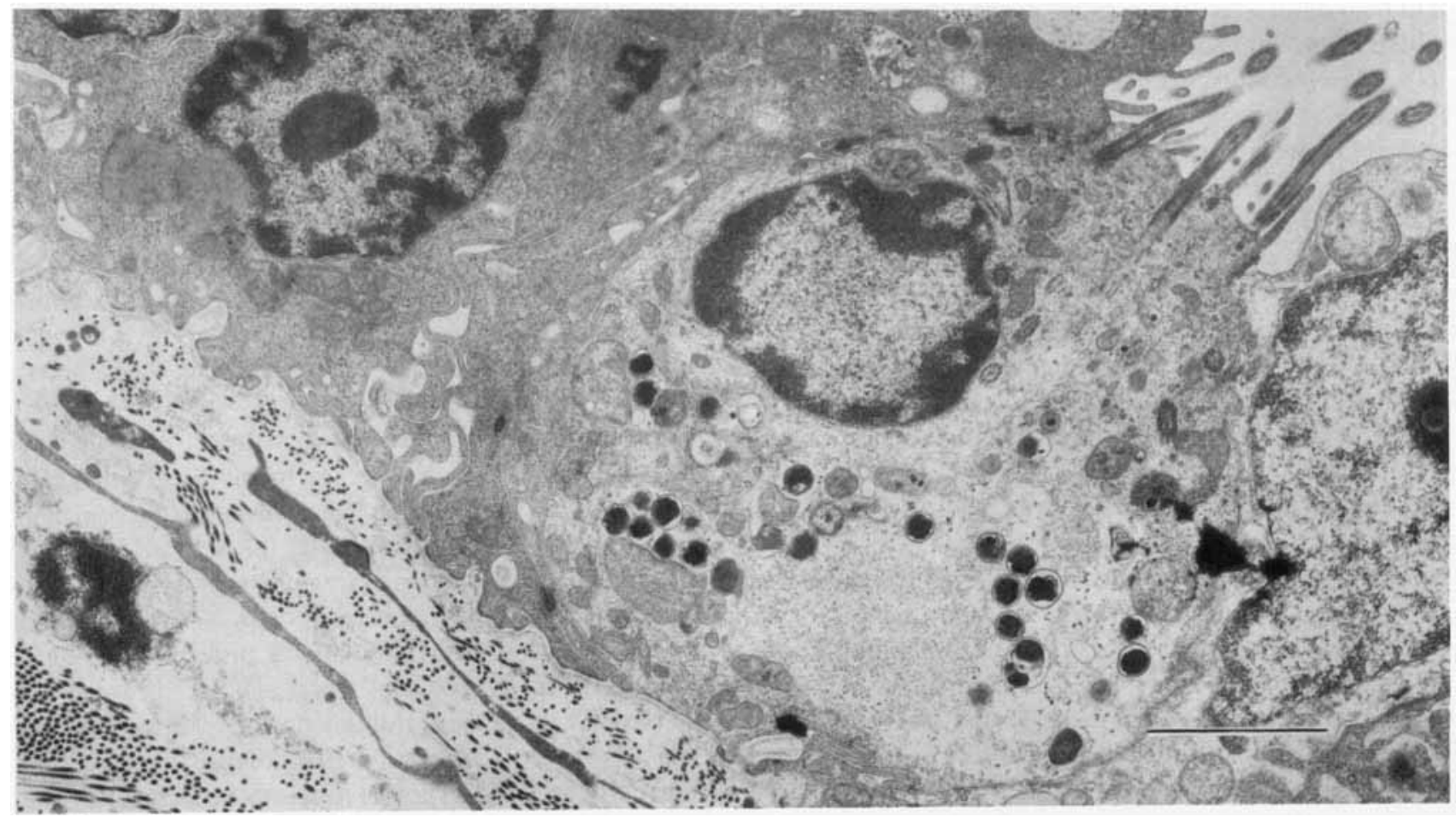

Fig. 6. Transmission electron micrograph of an infected ciliated epithelial cell at $72 \mathrm{~h}$ post-infection. Various forms of the developmental cycle are present. Bar, $2 \mu \mathrm{m}$. 
strated on long-term follow-up. In infected subcutaneous fimbrial transplants in cynomolgus and rhesus monkeys, C. trachomatis inclusions were detected within fimbrial epithelial cells up to $7 \mathrm{~d}$ post-inoculation by both fluorescent-antibody staining and immunoperoxidase techniques using $C$. trachomatis-specific monoclonal antibodies. $C$. trachomatis was recovered from the autografts up to $5 \mathrm{~d}$ after infection.

Swanson et al. (1975) demonstrated typical chlamydial inclusions in the columnar epithelium of cervical biopsy specimens obtained from patients who were culture positive for C. trachomatis and Neisseria gonorrhoeae. Moller et al. (1979) studied fallopian tubes removed from two patients with $C$. trachomatis salpingitis. TEM studies failed to reveal inclusions consistent with those produced by $C$. trachomatis. However, immunofluorescence studies showed intracytoplasmic chlamydial inclusions in some of the epithelial cells.

In an effort to further define the interactions between C. trachomatis and human fallopian tube mucosa, we performed a detailed microbiological and microscopic study of HFTOC infected with an E serovar of $C$. trachomatis. The data demonstrated that a sustained, albeit low-level, C. trachomatis infection occurs in the model. In contrast to gonococcal infection of HFTOC, where lipopolysaccharides and peptidoglycan monomers released from rapidly dividing gonococci extensively damage both ciliated and nonciliated epithelial cells (Stephens, 1989), infection of HFTOC with C. trachomatis had no overall effect on mucosal architecture or ciliary activity. These data support the results of Hutchinson $e t$ al. (1979), who found that ciliary activity of fallopian tube mucosa was not diminished by $C$. trachomatis infection. However, studies of human fallopian tubes removed during active chlamydial salpingitis demonstrate marked inflammation, loss of cilia, oedema and extensive disruption of the mucosal surface. Taken together, these data suggest the importance of the inflammatory response (not present in the in vitro HFTOC model) in the pathogenesis of $C$. trachomatis salpingitis and may indicate that $C$. trachomatis, unlike $N$. gonorrhoeae, may not secrete toxins which produce generalized mucosal damage.

We did observe local, direct cytotoxic effects of $C$. trachomatis on HFTOC mucosal cells. Early in the infection (4-8 h), attachment of mutiple $C$. trachomatis EBs to certain epithelial cells produced a loss of microvilli, disruption of cell borders and sloughing of these cells from the mucosal surface while adjacent cells were uninfected. Loss of epithelial cells with attached EBs appeared to be independent of the intracellular development cycle but the exact role of this event in $C$. trachomatis pathogenesis is unclear. These results are in sharp contrast to the attachment of gonococci to nonciliated epithelial cells of HFTOC, where interaction with microvilli is prominent and mucosal architecture with the adjacent cells is preserved (McGee et al., 1976; Ward et al., 1974). It should be emphasized that loss of microvilli and sloughing of epithelial cells occurred with multiple EBs whereas local cytotoxicity was not observed with attachment of individual EBs.

Moorman et al. (1986) used primary cultures of human endometrial and ectocervical epithelial cells to study genital infection of $C$. trachomatis. They noted a difference in the infection in McCoy cell versus genital cell cultures. C. trachomatis failed to adhere to many of the genital cell cultures whereas adherence to McCoy cells was uniform. Inocula which gave $50-80 \%$ infectivity (inclusion formation) of standard McCoy cells resulted in infection of $15-30 \%$ of columnar cells of the human endometrium and $5-10 \%$ of the squamous cells of the ectocervix. Exposure to DEAE-dextran and centrifugation did not enhance the number of inclusion-positive genital cells.

Our data would also suggest selectivity of C. trachomatis attachment and replication in epithelial cells of HFTOC. The low level of infectivity $(\sim 6 \%)$ of the epithelial cells may indicate that host factors may limit susceptibility of HFTOC to infection. Maslow et al. (1988) found that $C$. trachomatis would attach to approximately $50 \%$ of cultured human endometrial gland epithelial cells. The addition of oestrogen increased attachment rates to approximately $80 \%$, while progesterone in combination with oestrogen reduced chlamydial attachment in a dose-dependent fashion. Together these studies suggest a cellular specificity with respect to the attachment and replication of C. trachoma$t i s$ and that these events may be under hormonal influence.

In this study, we were unable to completely identify the events of entry of $C$. trachomatis into HFTOC mucosal cells or the events leading to formation of inclusions. However, LM of infected HFTOC revealed inclusions which were consistent with those seen in human cervical biopsy material (Swanson et al., 1975). Further, this study is the first to demonstrate by electron microscopy all developmental forms of $C$. trachomatis within an infected human fallopian tube mucosal cell. It is interesting that in some of our TEM studies apparent rupture of the inclusion occurred prior to release of $C$. trachomatis from the epithelial cells.

We believe that HFTOC is a unique and relevant model to study the pathogenesis of $C$. trachomatis salpingitis. Hormonal influence on $C$. trachomatis infectivity, effects of antibiotics, role of local immunocompetent cells, and evaluation of mutants with specific genetic lesions are among some of the studies possible using this model. 
We wish to acknowledge the expert technical assistance of Ms Peg Miles and Dr Suzanne Mirra of the Electron Microscopy Laboratory of the Veterans Administration Hospital, Atlanta, Georgia, and Ms Janice Bullard and Mr Shannon Mitchell of the Center for Disease Control. We also wish to acknowledge the help with tissue culture cell line and some specimens from the Memorial Medical Center Virology Laboratory and Jeanette Froschauer, and the editorial assistance and typing of Barb Reichert. Financial assistance was provided by Southern Illinois University School of Medicine research grant \#2-40224, by the Medical Research Service of the Veterans Administration and by the Cooperative Agreement USO/CCU 4008403 from the Centers for Disease Control and grant AI-20603 from National Institutes of Health.

\section{References}

Aral, S. O. \& Holmes, K. K. (1990). Epidemiology of sexual behavior and sexually transmitted diseases. In Sexually Transmitted Diseases, 2nd edn, p. 19-36. Edited by K. K. Holmes, P.-A. Mårdh, P. F. Sparling, P. J. Wiesner, W. Cates, Jr, S. M. Lemon \& W. E. Stamm. New York: McGraw-Hill.

Barron, A. L., White, H. J., Rank, R. G., Soloff, B. L. \& Moses, E. B. (1981). A new animal model for the study of Chlamydia trachomatis genital infections: infection of mice with the agent of mouse pneumonitis, Journal of Infectious Diseases 143, 63-66.

BIRD, B. R. \& FoRRESTER, F. T. (1981). Laboratory Diagnosis of Chlamydia trachomatis Infections, pp. 33-71. Atlanta: US Department of Health and Human Services.

Hutchinson, G. R., TAYloR-Robinson, D. \& Dourenashin, R. R (1979). Growth and effect of chlamydiae in human and bovine oviduct organ cultures. British Journal of Venereal Diseases 55 194-202.

Kuo, C.-C., Wang, S.-P. \& Grayston, J. T. (1972). Differentiation of TRIC and LGV organisms based on enhancement of infectivity by DEAE-dextran in cell culture. Journal of Infectious Diseases 125, 313-317.

Maslow, A. S., Davis, C. H., Choong, J. \& Wyrick, P. B. (1988). Estrogen enhances attachment of Chlamydia trachomatis to human endometrial epithelial cells in vitro. American Journal of Obstetrics and Gynecology 159, 1006-1014.

MCGee, Z. A., Johnson, A. P. \& TAYlor-Robinson, D. (1976). Human fallopian tubes in organ culture: preparation, maintenance, and quantitation of damage by pathogenic microorganisms. Infection and Immunity 13, 608-618.

Moller, B. R., Westrom, L., Ahrons, S., Ripa, K. T., Svensson, L., Von MeCKLendurg, C., HeNRICKSON, H. \& MARDH, P.-A. (1979). Chlamydia trachomatis infection of fallopian tubes: histological findings in two patients. British Journal of Venereal Diseases 55 , $422-428$.
MoORMan, D., SIXbeY, J. W. \& WYRICK, P. B. (1986). Interaction of Chlamydia trachomatis with human genital epithelium in culture. Journal of General Microbiology 132, 1055-1067.

PATTON, D. L. (1985). Immunopathology and histopathology of experimental chlamydial salpingitis. Reviews of Infectious Diseases 7 , 746-753.

Patton, D. L., Halbert, S. A., Kuo, C.-C., Wang, S.-P. \& Holmes, K. K. (1983). Host response to primary Chlamydia trachomatis infection of the fallopian tube in pig-tailed monkeys. Fertilization and Sterilization 40, 829-840.

Patton, D. L., Kuo, C.-C., Wang, S.-P., Brenner, P. M., Sternfeld, M. D., MoRSE, S. A. \& Barnes, R. C. (1987a). Chlamydial infection of subcutaneous fimbrial transplants in cynomolgus and rhesus monkeys. Journal of Infectious Diseases 155, 229-235.

Patton, D. L., Kuo, C.-C., Wang, S.-P. \& Halbert, S. A. (1987b). Distal tubal obstruction induced by repeated Chlamydia trachomatis salpingeal infections in pig-tailed macaques. Journal of Infectious Diseases 155, 1292-1299.

STEPHENS, D. S. (1989). Gonococcal and meningococcal pathogenesis as defined by human cell, cell culture, and organ culture assays. Clinical Microbiology Reviews 2, S104-S111.

Swanson, J., Eschenbach, D. A., Alexander, E. R. \& Holmes, K. K. (1975). Light and electron microscopic study of Chlamydia trachomatis infection of the uterine cervix. Journal of Infectious Diseases 131, 678-687.

Swenson, C. E., Donegan, E. \& Schachter, J. (1983). Chlamydia trachomatis-induced salpingitis in mice. Journal of Infectious Diseases 148, 1101-1109.

TUfFrey, M. \& TAYloR-Robinson, D. (1981). Progesterone as a key factor in the development of a mouse model for genital-tract infection with Chlamydia trachomatis. FEMS Microbiology Letters 12, 111-115.

TUFFREY, M., FALDER, P. \& TAYLOR-RobInSON, D. (1982). Genitaltract infection and disease in nude and immunologically competent mice after inoculation of a human strain of Chlamydia trachomatis. British Journal of Experimental Pathology 63, 539-546.

TUFfrey, M., FALDER, P. \& TAYLOR-Robinson, D. (1984). Reinfection of the mouse genital tract with Chlamydia trachomatis: the relationship of antibody to immunity. British Journal of Experimental Pathology 65, 51-58.

TUFFrey, M., FAlder, P. \& TAylor-Robinson, D. (1985). Effect on Chlamydia trachomatis infection of the murine genital tract of adoptive transfer of congenic immune cells or specific antibody. British Journal of Experimental Pathology 66, 427-433.

TufFrey, M., Falder, P., Gale, J. \& TAYloR-Robinson, D. (1986). Salpingitis in mice induced by human strains of Chlamydia trachomatis. British Journal of Experimental Pathology 67, 605-616.

Ward, M. E., WatT, P. J. \& Robertson, J. N. (1974). The human fallopian tube: a laboratory model for gonococcal infection. Journal of Infectious Diseases 129, 650-659.

Washington, A. E., Johnson, R. E. \& Sanders, L. L., JR (1987). Chlamydia trachomatis infections in the United States: what are they costing us? Journal of the American Medical Association 257, 2070-2072. 